\title{
Estimation of forest volumes by integrating Landsat TM imagery and forest inventory data
}

\author{
GU Huiyan ${ }^{1,2}$, DAI Limin ${ }^{1}$, WU Gang ${ }^{3}$, XU Dong ${ }^{1,4}$, WANG Shunzhong ${ }^{1,4}$ \\ \& WANG Hui ${ }^{1,4}$ \\ 1. Institute of Applied Ecology, Chinese Academy of Sciences, Shenyang 110016, China; \\ 2. School of Forestry, Northeast Forestry University, Harbin 150040, China; \\ 3. State Key Lab of Systems Ecology, Research Center for Eco-Environmental Sciences, Chinese Acad- \\ emy of Sciences, Beijing 100085, China; \\ 4. Graduate University of Chinese Academy of Sciences, Beijing 100039, China \\ Correspondence should be addressed to Wu Gang (email: wug@rcees.ac.cn) \\ Received October 10, 2005; accepted April 12, 2006
}

\begin{abstract}
Accurate information about forest volumes is essential for forest management planning. The survey interval of the Forest Resource Inventory of China (FRIC) is too long to meet the demand for timely decision-making required for forest protection, management, and utilization. Analysis of satellite imagery provides good potential for more frequent reporting of forest parameters. In this study, we describe an application of the $k$-nearest neighbors $(k N N)$ method to Landsat TM imagery for improving estimation of forest volumes. Several spectral features were tested and compared in forest volume estimations, including normalized difference vegetation index, environmental vegetation index, and the combination of the spectral features. The combined index resulted in the most accurate volume estimations. The $k N N$ estimator and the combined index were then used in forest volume estimation. The estimation error (RMSE) of the total volume was 44.2\%, much lower than those for Larix forest (the RMSE was 51.7\%) and those for the Korean pine and broadleaved forests (the estimation errors were over $71.7 \%$ and $88.19 \%$, respectively). This preliminary study demonstrates the potential of forest volume estimations with remote sensing data to provide useful information for forest management if only limited ground information is available.
\end{abstract}

Keywords: forest inventory, landsat TM, $k$-nearest neighbors, spectral extraction.

The national program of Forest Resource Inventory of China (FRIC), implemented by the Chinese Ministry of Forestry to survey China's forest resources, conducts regional surveys at approximately ten-year intervals. Both the definition and timber volume measurement of forests are based on the technical standards of the Forestry Ministry of 
China $^{[1]}$. These field measurements provide biotic factors, localities sample plot sizes. Ultimately, FRIC provides data on forest and related resources for all of China, and aims to provide timely information for the development of nationwide forest policies and programs for protection, management, and utilization of forest resources ${ }^{[2-5]}$.

Though the FRIC system has been used for nearly six decades, the survey adaptation has not kept pace with the changing information needs or advances in forest inventory technology. However, in recent years there have been major changes in forest monitoring systems in the international community. In the USA, the Forest Inventory and Analysis (FIA) program shifted from periodic resurveys to an annual system of field data collection and analysis ${ }^{[6,7]}$. They consider an annual inventory essential for the timely collection and analysis of forest inventory data ${ }^{[8]}$. In northern Europe, considerable effort has been made to develop techniques for wall-to-wall mapping of forest variables ${ }^{[9]}$. The Chinese Ministry of Forestry should refer to international technical standards of forest resource measurements to provide more timely and accurate estimations forest resources.

While quality forest resources in China are declining sharply, demands for sustainable forest management planning are becoming increasingly more important. This requires alternative forest resource inventories and monitoring to obtain reliable information about continuous changes in forest resources. Landsat TM satellite imagery has been used to estimate continuous forest parameters in many countries ${ }^{[10-16]}$. Remote sensing approaches provide great potential to improve the efficiency of current forest inventory methods in China. Tomppo ${ }^{[17]}$ applied the $k$-nearest neighbors $(k N N)$ method to producing localized estimates from the national forest inventory data of Finland, and then incorporated the method into the national forest inventory of Finland on an operational basis. In Scandinavian conditions, estimation errors were about $56 \%-68 \%^{[18,19]}$; Tokola and Heikkila ${ }^{[16]}$ reached an acceptable level of estimation error for total volume (ca. $20 \%$ ) when the inventory area exceeded 30 ha. Though the estimation error is a little high, the method shows great promise for estimation of forest volumes.

The overall objective of this paper is to develop and demonstrate an integrated method of using the $\mathrm{kNN}$ to improve forest volume estimations in northeast China. The accuracy of volume estimations by different methods is also investigated.

\section{Material and methods}

\section{1 kNN estimation procedure}

The $k \mathrm{NN}$ method is used here to generalize information from field plots to pixels for local area estimation. The method assumes that similar forest exists within a large reference area, represented within a satellite image, and that the spectral radiometric responses of image pixels are only dependent on the state of the forest. Several examples can be found in the literature ${ }^{[14,17]}$ and Tomppo has led efforts to incorporate the method in forest inventories ${ }^{[9]}$.

A general description of the $k \mathrm{NN}$ method follows. The spectral distance, $d_{p i} p$ is computed in the feature space from the pixel $p$ to be classified to each pixel pi for which the 
ground measurement or class is known. For each pixel $p$, take $k$-nearest field plot pixels (in the feature space) and denote the distances from the pixel $p$ to the nearest field plot pixels by $d_{p i}, p, \ldots, d_{p k}, p\left(d_{p i}, p \leqslant \cdots \leqslant d_{p k}, p\right)$. The estimate of the variable value for the pixel $p$ is then expressed as a function of the closest units, each such unit value weighted according to a distance function in a particular feature space. A commonly-used function for weighting distances is

$$
W_{\left(p_{i}\right) p}=\frac{1}{d_{\left(p_{i}\right) p}^{t}} / \sum_{j=1}^{k} \frac{1}{d_{\left(p_{i}\right) p}^{t}}
$$

with $t=2$. The estimate of the variable $m$ for pixel $p$ is then

$$
m_{p}=\sum_{i=1}^{k} w_{\left(p_{i}\right) p^{m}\left(p_{i}\right)},
$$

where $m\left({ }_{p i}\right), i=1, \cdots, k$, is the value of the variable $m$ in sample plot $i$ corresponding to the pixel $p_{(i)}$, which is the $i$ th closest pixel (of "known" pixels) in the spectral space to the pixel $p^{[9,20]}$.

\subsection{Study material}

The Baihe Forest Bureau, a forestry enterprise owned by the Chinese government, is located in Jilin Province, one of the most important wood-production provinces in China (Fig. 1). The development of forestry and the forest industries of the Baihe Forest Bureau is a key national project. The total land area managed by the Baihe Forest Bureau is 190,000 ha. The center of the bureau is located at $42^{\circ} 26.63^{\prime} \mathrm{N}, 128^{\circ} 26.56^{\prime} \mathrm{E}$. Ranging from 600 to $1,200 \mathrm{~m}$ in elevation, the native forest type in Baihe Forestry Bureau is mainly temperate, mixed-species forest. Extensive forest felling started in 1972 after this forestry bureau was established. The region's forests are important not only for timber

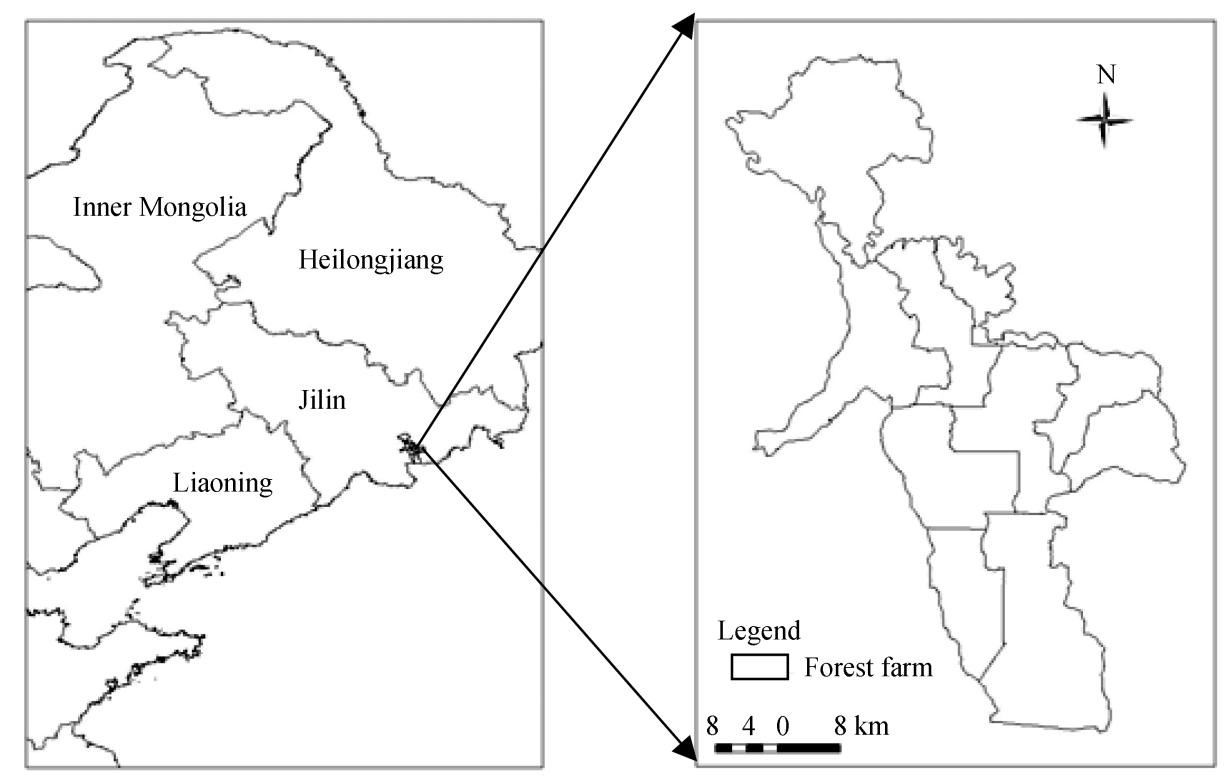

Fig. 1. The location of the Baihe Forestry Bureau. 
resources, but also as habitat for endangered wildlife species, such as the Manchurian tiger (Panthera tigris altaica) and Chinese merganser (Mergus squamatus) ${ }^{[21-23]}$.

Two Landsat TM scenes (WRS 116/30 and 116/31) acquired on Sept. 7, 1999, were used for this study. Image data were rectified to China's uniform coordinate system and re-sampled to a pixel size of $30 \mathrm{~m} \times 30 \mathrm{~m}$.

Ground data of the fifth Forest Resource Inventory of China, obtained in 1999, were used in the study. The positions of sample plots were located using bearings and distances measured from points identifiable on the ground and a 1:50,000 base map. The total number of sample plots in the study area was 1,030, all of which were located on forestry land and were completely inside their respective forest stands. All 1,030 plots or points were randomly divided into two groups, one for training (510 points) and the other for testing (520). The average volumes of different forest types represented by the sample points in the study area are summarized in Table 1 . (The relative standard error of the estimates of the main parameters in Table 1 for the whole area must be $\leqslant 5 \%$.)

Table 1 A summary of forest volumes from 1,030 FRIC sample plots $\left(\mathrm{m}^{3} / \mathrm{ha}\right)$

\begin{tabular}{lcccc}
\hline & Mean & S.D. & Min & Max \\
\hline Overall & 199.1 & 73.9 & 91.5 & 670.9 \\
Korean pine & 230.6 & 65.4 & 124.3 & 663.7 \\
Larix & 225.0 & 91.6 & 108.4 & 670.9 \\
Broadleaved & 97.2 & 80.4 & 112.8 & 342.3 \\
\hline
\end{tabular}

\subsection{Methods}

The spectral features for each sample plot were extracted from the nearest pixel of the plot location. A variety of spectral features of the forest stands were tested in the estimations of forest volumes. They include NDVI (normalized difference vegetation index), VI (vegetation index), EVI (environmental vegetation index); DN (digital number, i.e. pixel value) averages, DN averages and S.D., DN medians, DN medians and S.D. ${ }^{[24]}$, and a combination of DN, DN averages and S.D., DN medians, DN medians and S.D.

The $k$-nearest-neighbor $(k \mathrm{NN})$ estimation method was applied to the estimation of timber volumes ${ }^{[25]}$. The estimates were computed as a weighted mean of $k$ spectrally nearest neighbors that were proportionally weighted by the inverse squared Euclidean distance (eq. (3)). The weight was applied in order to decrease the bias of the $k \mathrm{NN}$ estimator $^{[24,26,27]}$.

$$
\hat{y}=\frac{\sum_{i=1}^{k}\left(1 / d_{i}^{2}\right) y_{i}}{\sum_{i=1}^{k}\left(1 / d_{i}^{2}\right)},
$$

where $\hat{y}$ is the estimate; $y_{i}$ the value of $y$ of the $i$ th nearest neighbor; $d_{i}$ the Euclidean distance to the $i$ th nearest neighbor and $k$ is the number of neighbors applied.

For every trial, the accuracy of our estimates of volume was examined using the root mean square error (RMSE) and bias (Bias) (eqs. (4) and (5) $)^{[28]}$ : 


$$
\begin{aligned}
& \text { RMSE }=\sqrt{\frac{\sum_{i=1}^{n}\left(\hat{y}_{i}-y_{i}\right)}{n},} \\
& \operatorname{Bias}=\frac{\sum_{i=1}^{n}\left(\hat{y}_{i}-y_{i}\right)}{n},
\end{aligned}
$$

where $\hat{y}_{i}$ is the estimate; $\hat{y}$ the mean of the estimates; the observed value of $y ; n$ the number of observations.

\section{Results}

\subsection{Determining the value of $k$}

Different values of $k$ were tested with the extracted spectral features (1.3 method) to determine the appropriate value of $k$ for the $k \mathrm{NN}$ estimation. Selected sets of RMSE curves are presented in Figs. 2 and 3. The RMSE of the volume estimates decreased rapidly as the number of nearest neighbors increased from 1 to 7 , but only slightly thereafter; thus a $k$ value of 7 was selected for further estimation.

The combination of features of DN, DN averages and S.D., DN medians, DN medians and S.D resulted in the lowest errors in estimation. There were no distinct differences in the precision of the estimation between the EVI and NDVI.

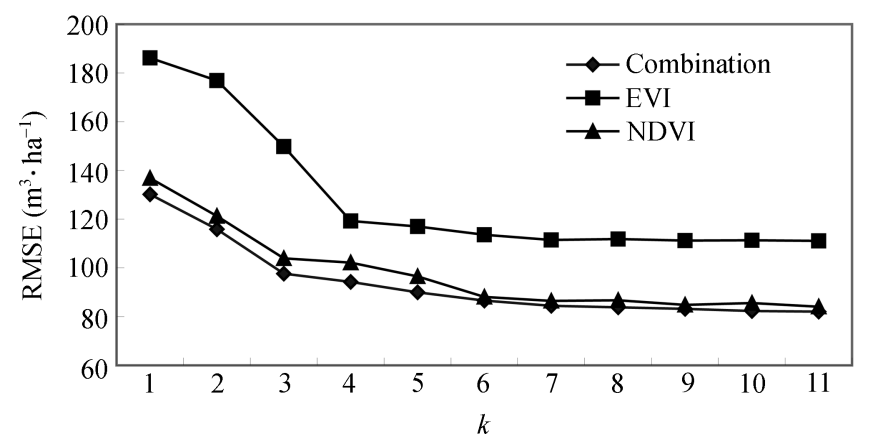

Fig. 2. The RMSE of volume estimations of the overall forests with different spectral features and different numbers of neighbors $(k)$.

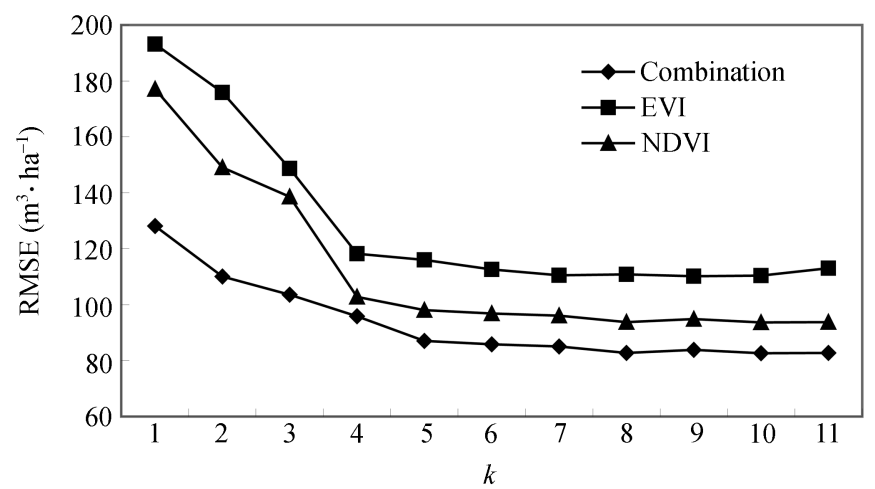

Fig. 3. The RMSE of volume estimations for the Larix forest with different spectral features and different numbers of neighbors $(k)$. 


\subsection{Volume estimations}

The spectral features that resulted in the two lowest RMSE curves were the Combination and NDVI. These two spectral features were selected for further analysis. EVI was employed as baselines in the evaluation of the performance of the Combination and NDVI. The volume estimations were tested with seven spectrally-nearest neighbors. This resulted in sufficient precision without averaging the results.

The most accurate estimations in forest volumes by the $k N N$ method were achieved by using the combined feature in the search for the nearest neighbors. The relative RMSE of the total volume estimates was $44.2 \%$ (Table 2 ). The RMSE of the total volume estimate with NDVI and EVI were 59.1 and $60.3 \%$, respectively.

Table 2 Errors of the total volume estimates using the different spectral features

\begin{tabular}{|c|c|c|c|c|c|c|c|c|}
\hline \multirow{3}{*}{ Feature selected } & \multicolumn{4}{|c|}{ Overall } & \multicolumn{4}{|c|}{ Larix Forest } \\
\hline & \multicolumn{2}{|c|}{ RMSE } & \multicolumn{2}{|c|}{ Bias } & \multicolumn{2}{|c|}{ RMSE } & \multicolumn{2}{|c|}{ Bias } \\
\hline & $\mathrm{m}^{3} / \mathrm{ha}$ & $\%$ & $\mathrm{~m}^{3} / \mathrm{ha}$ & $\%$ & $\mathrm{~m}^{3} / \mathrm{ha}$ & $\%$ & $\mathrm{~m}^{3} / \mathrm{ha}$ & $\%$ \\
\hline Combination & 82.3 & 44.2 & -12.96 & 6.9 & 95.09 & 51.7 & -41.2 & 22.4 \\
\hline NDVI & 110.4 & 59.1 & -13.37 & 7.1 & 132.4 & 78.2 & -27.4 & 16.1 \\
\hline EVI & 115.8 & 60.3 & -13.68 & 7.7 & 144.2 & 81.1 & -33.2 & 15.9 \\
\hline
\end{tabular}

Errors in the volume estimates by tree species were clearly higher than those of the total volume estimates. In the estimation, the Combination resulted in the lowest RMSE (Tables 2 and 3). The volume of Larix forest was estimated with a relative error of $51.7 \%$, while the estimation errors for the Korean pine and boadleaved tree species were over $71.7 \%$ and $88.19 \%$ respectively. The NDVI resulted in slightly better estimates than the EVI .

Table 3 Errors of the Korean pine and boadleaved volume estimates using the different spectral features

\begin{tabular}{|c|c|c|c|c|c|c|c|c|}
\hline \multirow{3}{*}{ Feature selected } & \multicolumn{4}{|c|}{ Korean pine } & \multicolumn{4}{|c|}{ Broadleaved } \\
\hline & \multicolumn{2}{|c|}{ RMSE } & \multicolumn{2}{|c|}{ Bias } & \multicolumn{2}{|c|}{ RMSE } & \multicolumn{2}{|c|}{ Bias } \\
\hline & $\mathrm{m}^{3} / \mathrm{ha}$ & $\%$ & $\mathrm{~m}^{3} / \mathrm{ha}$ & $\%$ & $\mathrm{~m}^{3} / \mathrm{ha}$ & $\%$ & $\mathrm{~m}^{3} / \mathrm{ha}$ & $\%$ \\
\hline Combination & 109.09 & 71.7 & -23.2 & 10.4 & 88.19 & 88.7 & -18.4 & 16.7 \\
\hline NDVI & 144.4 & 88.2 & -21.4 & 12.1 & 103.6 & 97.2 & -20.6 & 15.5 \\
\hline EVI & 157.2 & 93.1 & -19.2 & 11.9 & 117.2 & 103.1 & -18.1 & 20.4 \\
\hline
\end{tabular}

In the estimation of the total volume, the biases were positive with all the different feature sets and varied from $6.9 \%$ to $7.7 \%$ (Table 2 ). There was more variation in the biases of the volume estimates by tree species and, in general, they were higher than the biases of the total volume estimates. For example, when the Combination was employed, the Larix and Korean pine volumes were overestimated by $22.4 \%$ and $10.1 \%$, respectively (Tables 2 and 3).

\section{Discussion}

\subsection{Spectral features}

The objective of the study was to investigate the estimation of forest volumes by 
means of satellite image data and stand-level field data. The Combination of Landsat TM spectral features of forest stands gave the best estimation results. While the single spectral feature is not as expected to give best estimation, it is obviously important to select suitable spectral features for estimation when using $k$ NN Method.

\subsection{Number of neighbors}

The errors in $k \mathrm{NN}$ estimations of volume using neighbors and the response of RMSE are depicted in Figs. 2 and 3. It is clear that there was a rapid, early gain in overall precision with the addition of neighbors. The values for the RMSE dropped quickly when the number of neighbors was increased from one to five. After the number of neighbors reached seven, the marginal increase in precision was smaller. This result agrees with the findings of several other authors who reported this stability point between 5 and 15 neighbors $^{[14,24]}$.

\subsection{Estimation results}

In fact, the standard errors of volume estimates were high. The RMSE of total volume was at best $44.2 \%$, but the results are comparable to other studies of the $k \mathrm{NN}$ estimation using with field data assessed by sample plots. For example, at the forest stand level, Tokola $^{[16]}$ and Hyyppa et al. ${ }^{[18]}$ reported RMSE forest volume was approximately $40 \%$ and $56 \%$ respectively. Better estimation results have been obtained for larger forest stands. In a study by Holmgren ${ }^{[11]}$ the RMSE of stem volume was $36 \%$ when the average size of forest stands was 19 ha. Estimates of volumes by tree species are usually less accurate than estimates of the total forest volume ${ }^{[14]}$. In this study, the errors of volume estimated by tree species were also higher than those estimated by total volume.

In addition, the numbers of forest stands in both the training and test data sets affect volume estimation. Using too few stands in the training data may have a negative effect on the results because the material may not be representative for the area. Nilsson ${ }^{[14]}$ preferred to use 1000 sample plots in the $k \mathrm{NN}$ estimation.

The small size of forest stands restricts the applicability of low-resolution satellite data in the estimation of forest stand parameters. For example, if maximum acceptable error for stand volume estimation is $20 \%$, and Landsat TM imagery (geographical resolution $30 \mathrm{~m} \times 30 \mathrm{~m}$ ) are used, the size of sample plots must exceed $30 \mathrm{ha}^{[16]}$. For forest stands of $1-3$ ha in size, only rough estimates can be obtained.

In spite of high RMSE, the $k \mathrm{NN}$ method is very promising for quantifying forest volume estimates up to the landscape scale. Through its simplicity and ease of application, this method provides a very feasible tool for local- to landscape-level estimation. The costs of forest surveys could be significantly reduced by supplementing or replacing field surveys with estimation methods using satellite imagery.

The methods presented have several important advantages. Analysts have long been seeking techniques enabling combination of inventory sources. The $k \mathrm{NN}$ method is a versatile technique with potential for combining different sources of information, not only from outside of a region of interest, but even from different forest inventory designs. The combination of different remote sensors is straightforward since the method is based 
solely on the search for similar units. Furthermore, since location in the field is the main relational feature of the $k \mathrm{NN}$ technique, priority should be given to obtaining precise geospatial location information.

The method tested in this study might be more applicable to areas where forests are more homogeneous and form larger stands, rather than in fragmented forests. If high-accuracy, stand-level information is required, aerial photographs or other high-spatial-resolution images may provide less error-prone survey estimates.

Acknowledgements This project was supported by the National Natural Science Foundation of China (Grant Nos. 30470302 and 70373044). We would like to thank Dr. Donald R. Drake and Timothy Edmonds for polishing the English.

\section{References}

1 Forestry Ministry of China. Technical Standards for Forest Resource Measurement (in Chinese). Beijing: China Forestry Publishing House, 1983

2 Department of Forest Resource and Management, Chinese Ministry of Forestry, Forest Resources of China 1949-93 (in Chinese), Beijing, Department of Forest Resource and Management, Chinese Ministry of Forestry, 1996

3 Fang J Y, Chen A P, Peng Ch H, et al. Changes in forest biomass carbon storage in China between 1949 and 1998. Science, 2001, (292): 2320-2322

4 Wu G, Xiao H, Zhao J Z, et al. Forest ecosystem services of Changbai Mountains in China. Sci China Ser C-Life Sci, 2002, 45(1): 21-32

5 Liu J Y, Xu X L, Zhuang D F, et al. Impacts of LUCC processes on potential land productivity in China in the 1990s. Sci China Ser D-Earth Sci, 2005, 48(8): 1259-1269

6 McRoberts R E. The joint annual forest inventory and monitoring system: the north central perspective. J Forest, 1999, 97(12): 27-31

7 Reams G A, Roesch F A, Cost N D. The cornerstone of southern forest sustainability: annual forest inventories. J Forest, 1999, 97(12): 21-26

8 Anonymous, Forest inventory and analysis program. The report of the second Blue Ribbon panel. Washington, DC: American Forest and Paper Association, 1998

9 Franco-Lopez H, Alan R Ek, Marvin E B. Estimation and mapping of forest stand density, volume, and cover type using the $k$-nearest neighbors method. Remote Sens Environ, 2001, 77: 251-274

10 Boyd D S, Danson F M. Satellite remote sensing of forest resources: three decades of research development. Progr Phy Geogr, 2005, 29(1): 1-26

11 Holmgren J, Joyce S, Nilsson M, et al. Estimating stem volume and basal area in forest compartments by combining satellite image data with field data. Scandinavian J Forest Res, 2000, 15: 103-111

12 Holmgren P, Thuresson T. Satellite remote sensing for forestry planning - a review. Scandinavian J Forest Res, 1998, 13: $90-110$

13 Katila M, Tomppo E. Selecting estimation parameters for the Finnish multi-source national forest inventory. Remote Sens Environ, 2001, 76(1): 16-32

14 Nilsson M, Estimation of forest variables using satellite image data and airborne lidar. Doctoral Theses. Department of Forest Resource Management and Geomatics, Swedish University of Agricultural Sciences, Umea, 1997

15 Jin Y Q. Radiative transfer theory at satellite-borne SSM/I channels and remote sensing data analysis. Sci China Ser E-Eng Mater Sci, 1997, 40(6): 644-652

16 Tokola T, Heikkila J. Improving satellite based forest inventory by using a priori site quality information. Silva Fennica, 1997, 1(31): 67-78 
17 Tomppo E. Satellite image-based national forest inventory of Finland. Int Archi Photogr Remote Sens, 1991, 28(7-1): 419-424

18 Hyyppa J, Hyyppa H, Inkinen M, et al. Accuracy comparison of various remote sensing data sources in the retrieval of forest stand attributes. For Ecol Manage, 2000, 128: 109-120

19 Kilpelainen P, Tokola T. Gain to be achieved from stand lineation in Landsat TM image-based estimates of stand volume. For Ecol Manage, 1999, 124: 105-111

20 Tomppo E. Application of remote sensing in Finnish national forest inventory. In: Application of remote sensing in European forest monitoring. International Workshop Proceedings, Vienna: European Commission, CL-NA-17685-EN-C (14-16 October 1996), 1997. 375-388

21 Shao G F, Wang H, Dai L M, et al. Integrating stand and landscape decisions for multi-purposes of forest harvesting, For Ecol Manage, 2005, 207: 233-243

22 Dai L M, Shao G F, Zhou L, et al. The roles of a decision support system in applying forest ecosystem management in northeast China. Sci China Ser E, 2006, 49(supp. I): 9-18

23 Shao G F, Wang F, Dai L M, et al. A density-dependent matrix model and its applications in optimizing harvest scheme, Sci China Ser E, 2006, 49(supp. I): 108-117

24 Makela H, Pekkarinen A. Estimation of forest stand volumes by Landsat TM imagery and stand-level field-inventory data. For Ecol Manage, 2004, 196: 245 - 255

25 Keller J, Gray M, Givens J J. A fuzzy k-nearest neighbor algorithm. IEEE Transa Magn. Cybernetics, 1985, 15(4): $580-585$

26 Altman N. Introduction to kernel and nearest-neighbour nonparametric regression. Am Stat, 1992, 46(3): 175184

27 Makela H, Pekkarinen A. Estimation of timber volume at the sample plot level by means of image segmentation and Landsat TM imagery, Remote Sens Environ, 2001, 77: 66-75

28 Lindgren B W. Statistical Theory, 3rd ed. New York: Macmillan Publishing Co Inc, 1976, 614 